BMJ Open

Diabetes

Research

\& Care

\title{
Lifetime duration of lactation and chronic inflammation among middle- aged women with a history of gestational diabetes
}

\author{
Sylvia H Ley (D) , ${ }^{1}$ Jorge E Chavarro, ${ }^{2,3}$ Stefanie N Hinkle, ${ }^{4}$ Mengying Li (D) , \\ Michael Y Tsai, ${ }^{5}$ Frank B Hu, ${ }^{2,3}$ Cuilin Zhang ${ }^{4}$
}

To cite: Ley SH, Chavarro JE, Hinkle SN, et al. Lifetime duration of lactation and chronic inflammation among middle-aged women with a history of gestational diabetes. BMJ Open Diab Res Care 2020;8:e001229. doi:10.1136/ bmjdrc-2020-001229

- Supplemental material is published online only. To view, please visit the journal online (http://dx.doi.org/10.1136/ bmjdrc-2020-001229).

Received 27 January 2020 Revised 24 June 2020 Accepted 30 July 2020
Check for updates

(C) Author(s) (or their employer(s)) 2020. Re-use permitted under CC BY-NC. No commercial re-use. See rights and permissions. Published by BMJ.

For numbered affiliations see end of article.

Correspondence to Dr Sylvia H Ley; sley@tulane.edu and Dr Cuilin Zhang;

zhangcu@mail.nih.gov

\section{ABSTRACT}

Introduction Longer duration of lactation is associated with lower cardiometabolic disease risk, but pathogenic pathways involved in the disease progression are unclear, especially among high-risk women. We aimed to examine the associations of lifetime lactation duration with cardiometabolic biomarkers among middle-aged women with a history of gestational diabetes (GDM).

Research design and methods Women with a history of GDM participating in the Nurses' Health Study II, a prospective cohort study, were identified and followed through biennial questionnaires beginning in 1991. Lactation history was asked in three follow-up questionnaires to calculate lifetime duration. In 20122014, fasting blood samples were collected through the Diabetes \& Women's Health Study to measure inflammatory (C-reactive protein (CRP), interleukin (IL) 6), liver enzyme (alanine aminotransferase, aspartate aminotransferase, and gamma-glutamyl transferase), and lipid biomarkers (total cholesterol, low-density lipoprotein cholesterol, and high-density lipoprotein cholesterol).

Results At follow-up blood collection, women were at median age 58.2 (95\% Cl 51 to 65$)$ years and 26.3 (95\% Cl 15.7 to 34.1 ) years since GDM index pregnancy. After multiple adjustment including prepregnancy body mass index (BMI), longer duration of lactation was significantly associated with lower CRP (least squares (LS) mean $1.90 \mathrm{mg} / \mathrm{L}(95 \% \mathrm{Cl} 1.47$ to 2.45$)$ for 0-month lactation, $1.98 \mathrm{mg} / \mathrm{L}(95 \% \mathrm{Cl} 1.68$ to 2.32$)$ for up to 12 -month lactation, $1.67 \mathrm{mg} / \mathrm{L}(95 \% \mathrm{Cl} 1.42$ to 1.97$)$ for $12-24$ month lactation, and $1.39 \mathrm{mg} / \mathrm{L}(95 \% \mathrm{Cl} 1.19$ to 1.62$)$ for $>24$-month lactation; $p$ trend $=0.003)$ and IL-6 $(1.25 \mathrm{pg} / \mathrm{L}$ $(95 \% \mathrm{Cl} 0.94$ to 1.68$), 1.19 \mathrm{pg} / \mathrm{L}$ (95\% $\mathrm{Cl} 0.99$ to 1.42$)$, $1.04 \mathrm{pg} / \mathrm{L}(95 \% \mathrm{Cl} 0.87$ to 1.25$)$, and $0.93 \mathrm{pg} / \mathrm{L}(95 \% \mathrm{Cl}$ 0.78 to 1.11 ); $p$ trend $=0.04$ ). Longer duration of lactation was associated with lower risk for chronic inflammation using CRP $3 \mathrm{mg} / \mathrm{L}$ cut-off in middle-aged women (OR 0.81 ( $95 \% \mathrm{Cl} 0.69$ to 0.940 per 1 -year increase) with multiple adjustment.

Conclusions Longer lifetime duration of lactation was associated with favorable inflammatory biomarker concentrations in middle-aged women with a history of GDM. Chronic inflammatory pathways may be responsible for previously reported associations between lactation and long-term risk for cardiometabolic diseases.

\section{Significance of this study}

What is already known about this subject?

- Longer duration of lactation is associated with lower cardiometabolic disease risk, but pathogenic pathways involved in the disease progression are unclear, especially among high-risk women.

What are the new findings?

- Longer lifetime duration of lactation was associated with favorable inflammatory biomarker concentrations in middle-aged women with a history of gestational diabetes (GDM).

- Longer duration of lactation was associated with lower risk for chronic inflammation using C-reactive protein $3 \mathrm{mg} / \mathrm{L}$ cut-off in middle-aged women.

- Chronic inflammatory pathways may be responsible for previously reported associations between lactation and long-term risk for cardiometabolic diseases.

How might these results change the focus of research or clinical practice?

- The current investigation further contributes to the growing evidence that breast feeding has an important role in women's health.

- Continued investigation on the long-term consequences of breast feeding and other behavioral risk factors during reproductive years is warranted from the perspectives of the receiving offspring and from the offering women, especially those who are at high risk for cardiometabolic diseases.

\section{INTRODUCTION}

Cardiometabolic disease often manifests in older adulthood, but it is a progressive disease that has established risk factors emerging in younger adulthood. ${ }^{1}$ The majority of these risk factors are shared by both women and men, ${ }^{1}$ but women have distinctive sex-based biology and behavioral exposures including pregnancy-related events. ${ }^{2}{ }^{3}$ Women with a prior history of gestational diabetes (GDM), defined as diabetes diagnosed in the second or third trimester of pregnancy that was not 
clearly overt diabetes prior to gestation, ${ }^{4}$ are at higher risk for cardiometabolic disease progression. ${ }^{56}$ Longer duration of lactation during reproductive years has been associated with lower risk for cardiometabolic diseases including hypertension, type 2 diabetes, cardiovascular disease (CVD) risk and mortality in older adulthood. ${ }^{7-14}$ Therefore, there is a need to determine modifiable risk factors and relevant pathways to improve cardiometabolic health of aging women who have been identified as higher risk during reproductive years.

Growing data support the potential role of breast feeding, which has the main purpose of supporting child growth and development, on influencing lactating women's cardiometabolic health. ${ }^{12}{ }^{15-17}$ However, evidence is limited on specific cardiometabolic disease progression pathways, including chronic inflammation, dyslipidemia, and liver dysfunction, that may be influenced by lactation. Previously, duration of lactation and cardiometabolic biomarkers at 3 years after the index pregnancy were investigated in young women in their $30 \mathrm{~s},{ }^{18}$ and the study reported no significant association between lactation duration and inflammatory biomarker assessed by C-reactive protein (CRP) concentrations. However, the mean CRP concentrations were low across these young women, ${ }^{18}$ and therefore, the longer term impact in the disease progression remains unknown. In addition, inflammatory pathways may be more relevant for women with a history of GDM because GDM is often considered as manifestation of inflammation induced by physiological stress during pregnancy. ${ }^{19}$ Similarly, no associations reported between lactation duration and lipid profile in the previous study ${ }^{18}$ warrant further investigation among older women at higher risk for cardiometabolic disease. Longer lactation duration was recently associated with lower risk for non-alcoholic fatty liver disease in women. ${ }^{20}$ Since elevated liver enzyme biomarkers are known predictors for CVD risk, ${ }^{21}$ they may also be a marker for identifying the specific pathways implicated in cardiometabolic health benefits among high-risk women who breast feed. Therefore, we examined the associations of lifetime duration of lactation with cardiometabolic biomarkers, potentially involved in cardiometabolic pathogenic pathways such as inflammatory ${ }^{22}$ liver enzyme, ${ }^{21}$ and lipid metabolic biomarkers, ${ }^{23}$ among middle-aged women with a history of GDM. We hypothesize that longer duration of lactation will be associated with favorable inflammatory, liver enzyme, and lipid biomarker concentrations later in life.

\section{METHODS}

\section{Study population}

The Nurses' Health Study (NHS) II is an ongoing prospective cohort of 116671 female registered nurses from the USA aged 25-42 years in 1989. Participants were followed biennially using validated questionnaires on medical history and lifestyle. NHS II participants were eligible for inclusion in the current study if they reported a history of
GDM at the current analysis baseline in 1991 or incident GDM through the biennial questionnaires up to 2001 or through 2009 pregnancy questionnaire, which inquired about the physician's diagnoses of GDM. In a review of medical records among 120 women, $94 \%$ of self-reported GDM were confirmed. ${ }^{24}$ In a random sample of parous women $(n=100)$, a high level of GDM surveillance was documented in this cohort with $83 \%$ reporting to have undergone a glucose challenge test during pregnancy and $100 \%$ reporting frequent prenatal urine screening. The NHS II participants who reported a history of GDM were invited to participate in the Diabetes \& Women's Health Study (DWH), and details of the DWH Study protocol have been published previously. ${ }^{25}$ Briefly, blood samples were collected from 934 DWH Study participants from the NHS II in 2012-2014. ${ }^{25}$ After excluding those with cancer or CVD diagnosis before GDM index pregnancy $(n=24), 689$ women in total were included in the current analysis.

\section{Exposure assessments}

Lactation history was asked in three NHS II follow-up questionnaires. In 1993, participants were asked 'how many months in total (all births combined) did you breastfeed?' with response options: did not breast feed, $<1,1-3,4-6,7-11,12-17,18-23,23-35,36-47, \geq 48$, and cannot remember. Similar questionnaires were sent in 1997 and 2003 to update and overwrite lactation information with the latest response. Total duration of lactation was calculated based on the sum of the number of months after each birth that the participant reported stopping breast feeding completely.

Information on other potential cardiometabolic risk factors including medical, demographic, reproductive, lifestyle practices and body weight was collected through NHS II biennial questionnaires. The validity of these assessments has been documented previously. ${ }^{26}$ Parity was defined as the number of pregnancies lasting greater than 6 months. Menopausal status was captured by asking biennially whether the participants' menstrual periods had ceased permanently. Self-reported menopause status was highly reproducible in a validation study from a similar cohort of nurses. ${ }^{27}$ Age at first birth was collected through NHS II biennial questionnaire in 2007. To reflect earliest available lifestyle information during reproductive years, lifestyle data collected in 1991 were used. Dietary intake was assessed using a validated semiquantitative food frequency questionnaire in 1991, 2829 and diet quality was assessed using the Alternate Healthy Eating Index 2010 score. ${ }^{30}$ Physical activity was asked in 1991, and metabolic equivalent task hours per week was derived. ${ }^{31}$ As a surrogate prepregnancy body mass index (BMI) measure, BMI at age 18 years was calculated as self-reported weight $(\mathrm{kg})$ at age 18 years divided by the square of height $\left(\mathrm{m}^{2}\right)$. Based on the previous validation study, self-reported weights were highly correlated with measured weights $(\mathrm{r}=0.97){ }^{32}$ 


\section{Biochemical analyses}

Blood sample collection was described in detail previously. ${ }^{25}$ Briefly, a phlebotomy kit and instructions for fasting blood collection were sent to participants in 20122014. Samples were returned via overnight shipping to a central laboratory where blood was processed according to standardized procedures and stored at $-80^{\circ} \mathrm{C}$. Inflammatory (CRP and interleukin (IL) 6), liver enzyme (alanine aminotransferase (ALT), aspartate aminotransferase (AST), and gamma-glutamyl transferase (GGT)), and lipid biomarkers (total cholesterol, low-density lipoprotein cholesterol (LDL-C), and high-density lipoprotein cholesterol (HDL-C)) were measured at an accredited laboratory at the University of Minnesota.

CRP concentrations were measured using a highsensitivity Immunoturbidimetric assay (Roche COBAS 6000 chemistry analyzer, Roche Diagnostics, Indianapolis, Indiana, USA; interassay coefficient of variation (CV) $6.7 \%$ at $3.12 \mathrm{mg} / \mathrm{L}$ and $5.1 \%$ at $1.05 \mathrm{mg} / \mathrm{L}$ ). IL-6 concentrations were measured using Quantikine ELISA (R\&D Systems, Minneapolis, Minnesota, USA; interassay CV 4.7\%, 3.6\%, and $4.0 \%$ at means concentrations of 31,94 , and $197 \mathrm{pg} / \mathrm{mL}$ ). ALT (interassay CV $2.4 \%$ at $21 \mathrm{U} / \mathrm{L}$ and $2.0 \%$ at $133 \mathrm{U} / \mathrm{L})$, AST $(2.4 \%$ at $21 \mathrm{U} / \mathrm{L}$ and $2.0 \%$ at $141 \mathrm{U} / \mathrm{L})$ and GGT $(2.4 \%$ at $25 \mathrm{U} / \mathrm{L}$ and $1.7 \%$ at $174 \mathrm{U} / \mathrm{L}$ ) were measured using Roche COBAS 6000 chemistry analyzer (Roche Diagnostics). Cholesterol (interassay $\mathrm{CV} 2.1 \%$ at $178.6 \mathrm{mg} / \mathrm{dL}$ and $2.2 \%$ at $258.9 \mathrm{mg} / \mathrm{dL})$, HDL-C $(3.2 \%$ at $27.0 \mathrm{mg} / \mathrm{dL}$ and $1.9 \%$ at $51.7 \mathrm{mg} / \mathrm{dL}$ ) and LDL-C were assessed using Roche COBAS 6000 chemistry analyzer (Roche Diagnostics).

\section{Statistical analyses}

Distributions of continuous variables were assessed for normality, and natural log transformations of skewed biomarkers were used in subsequent analyses. Descriptive statistics for continuous variables were summarized as mean $\pm \mathrm{SD}$, and categorical variables were summarized using proportions according to duration of lactation categories $(0,1-12,12-24$, and $>24$ months).

General linear models were used to assess associations of lactation duration with cardiometabolic biomarkers. Model 1 was adjusted for age at follow-up to reflect the timing of blood collection (continuous). Model 2 was additionally adjusted for ethnicity (white/non-white), family history of diabetes (yes/no), lifetime parity (continuous), age at first birth $(<25,25-29,30-34$, and $\geq 35$ years), and menopausal status at follow-up blood draw (yes/no). Model 3 was adjusted for model 2 in addition to ever smoking assessed in 1991 (yes/no), diet quality assessed in 1991 (high/low), physical activity assessed in 1991 (high/low), and prepregnancy BMI $(\leq 25,25-30$, and $\left.>30 \mathrm{~kg} / \mathrm{m}^{2}\right)$. For age at first birth $(<1 \%$ missing), missing indicator was generated to treat missing as a separate category. Multiple logistic regression was conducted to evaluate the association of lactation duration with chronic inflammation at high risk for CVD using CRP
$3 \mathrm{mg} / \mathrm{L}$ cut-off by American Heart Association, ${ }^{33}$ with the same covariate adjustment.

Potential interactions were tested by adding an interaction term of lactation duration (continuous) with age (continuous), parity (continuous), primipara (yes/no), prepregnancy BMI (continuous), age at index GDM diagnosis (continuous), and duration since index GDM at blood draw (continuous) with adjustment for covariates included in model 2. Sensitivity analysis among participants free of type 2 diabetes at follow-up defined as hemoglobin $\mathrm{A} 1 \mathrm{C}<6.5 \%$ was considered. For all statistical analyses, two-sided $\mathrm{p}<0.05$ was considered to be statistically significant, except for interaction terms for which $\mathrm{p}<0.01$ was used to reduce the likelihood of false positive interactions. All data analyses were performed using SAS software, V.9.4 for UNIX.

\section{RESULTS}

For the current analysis, DWH Study participants in NHS II with lactation information and biomarkers of interests were included, as described in detail under methods. Baseline characteristics of those who provided blood samples were similar to the entire study population of women with a history of GDM. At follow-up blood collection, participants were at median age 58.2 (95\% CI 51 to 65 ) years and 26.3 (95\% CI 15.7 to 34.1 ) years since GDM index pregnancy. Among 689 women, 609 (88.4\%) reported lactating for at least 1 month in their lifetime. Characteristics of participants are presented according to the duration of lactation categories (table 1). Participants with longer lifetime duration of lactation tended to have a slightly higher number of parity and lower prepregnancy BMI.

\section{Lactation duration and biomarkers of inflammation, lipid, and} liver enzyme

Multiple regression models were constructed to assess whether duration of lactation was associated with cardiometabolic biomarkers (table 2). After multiple adjustment for age at follow-up blood draw, ethnicity, family history of diabetes, parity, age at first birth, menopausal status at follow-up blood draw, ever-smoking, diet quality, physical activity, and prepregnancy BMI (model $3)$, longer duration of lactation was significantly associated with CRP (LS mean $1.90 \mathrm{mg} / \mathrm{L}$ (95\% CI 1.47 to 2.45) for 0-month lactation, $1.98 \mathrm{mg} / \mathrm{L}$ (95\% CI 1.68 to 2.32) for up to 12-month lactation, $1.67 \mathrm{mg} / \mathrm{L}$ (95\% CI 1.42 to 1.97) for $12-24$ month lactation, and $1.39 \mathrm{mg} / \mathrm{L}(95 \%$ CI 1.19 to 1.62 ) for $>24$-month lactation; $p$ trend $=0.003$ ) and IL-6 $(1.25 \mathrm{pg} / \mathrm{L}(95 \%$ CI 0.94 to 1.68$), 1.19 \mathrm{pg} / \mathrm{L}$ (95\% CI 0.99 to 1.42 ), $1.04 \mathrm{pg} / \mathrm{L}$ (95\% CI 0.87 to 1.25 ), and $0.93 \mathrm{pg} / \mathrm{L}(95 \%$ CI 0.78 to 1.110$)$; $\mathrm{p}$ trend=0.04), while non-significant associations were observed with liver enzyme biomarkers (table 2). Although HDL, LDL, and total cholesterol were not significantly associated after adjustment for model 3, the mild significant association was observed with triglycerides $(p$ trend $=0.04$ ). 
Table 1 Characteristics of Nurses' Health Study II - Diabetes and Women's Health Study participants according to lifetime duration of lactation $(n=689)^{\star}$

\begin{tabular}{lllll}
\hline & \multicolumn{4}{l}{ Lifetime duration of lactation (months) } \\
\cline { 2 - 5 } & $\mathbf{0}$ & $\mathbf{1 - 1 2}$ & $\mathbf{1 2 - 2 4}$ & $\mathbf{2 4}$ \\
\hline $\mathrm{n}$ & 80 & 234 & 181 & 194 \\
\hline Age at index GDM†, years & $32.1 \pm 4.8$ & $32.6 \pm 4.7$ & $32.6 \pm 5.2$ & $33.1 \pm 4.8$ \\
\hline White & 88 & 93 & 92 & 94 \\
\hline Family history of diabetes & 33 & 28 & 28 & 28 \\
\hline Parity & $1.9 \pm 0.9$ & $1.7 \pm 0.8$ & $2.2 \pm 0.8$ & $3.0 \pm 1.3$ \\
\hline Age at first birth, years & $26.8 \pm 5.6$ & $29.5 \pm 5.7$ & $28.0 \pm 5.2$ & $26.3 \pm 4.2$ \\
\hline Prepregnancy body mass index, $\mathrm{kg} / \mathrm{m}^{2}$ & $22.3 \pm 4.6$ & $21.1 \pm 3.2$ & $20.9 \pm 2.8$ & $20.8 \pm 2.4$ \\
\hline Ever-smoking status in 1991 & 30 & 27 & 25 & 29 \\
\hline Alternate Healthy Eating Index in 1991 & $42.0 \pm 9.9$ & $45.3 \pm 11.2$ & $45.4 \pm 10.1$ & $43.9 \pm 9.8$ \\
\hline Total activity in 1991, METs/week & $14.6 \pm 14.7$ & $16.9 \pm 18.2$ & $17.5 \pm 17.7$ & $16.5 \pm 21.1$ \\
\hline
\end{tabular}

*Values are means \pm SD or percentages and are standardized to the age distribution of the study population. †Value is not age adjusted.

GDM, gestational diabetes; MET, metabolic equivalent task.

The associations of lactation duration with inflammatory biomarkers remained significant after additionally adjusting model 3 with age at index GDM diagnosis, duration since index GDM at blood draw, or type 2 diabetes at follow-up. Furthermore, no significant effect modification was observed for the association between lactation duration and the biomarkers by age at blood draw, parity, primipara, prepregnancy BMI, age at index GDM diagnosis, or duration since index GDM at blood draw.

\section{Lactation duration and risk for chronic inflammation}

Multiple logistic regression models were constructed to assess the association between lactation duration and chronic inflammation defined as CRP concentrations above $3 \mathrm{mg} / \mathrm{L}$ (table 3 ). A total of $33.2 \%$ women (224 of 675) had chronic inflammation at follow-up blood collection. Longer duration of lactation was associated with lower risk for chronic inflammation in middleaged women (OR 0.81 (95\% CI 0.69 to 0.94) per 1-year increase) with adjustment for age at follow-up blood draw, ethnicity, family history of diabetes, parity, age at first birth, menopausal status at follow-up blood draw, ever-smoking, diet quality, physical activity, and prepregnancy BMI (table 3). When we adjusted for changes in BMI from age 18 years to follow-up instead of adjusting for prepregnancy BMI in model 3, longer duration of lactation remained significantly associated with lower risk for chronic inflammation in middle-aged women (OR 0.84 (95\% CI 0.71 to 0.99 ) per 1-year increase). In a sensitivity analysis among women free of type 2 diabetes at follow-up (A1C $<6.5 \%$; $=562$ ), the significant associations between lactation duration and chronic inflammation remained (OR 0.79 (95\% CI 0.66 to 0.94 ) per 1-year increase) (online supplemental table). In a sensitivity analysis among women free of high blood pressure at follow-up $(\mathrm{n}=324)$, the significant association also remained (OR 0.76 (95\% CI 0.63 to 0.93 ) per 1-year increase), with adjustment for model 3 .

\section{DISCUSSION}

Longer lifetime duration of lactation was associated with favorable inflammatory biomarker concentrations in middle-aged women, after adjustment for sociodemographic, reproductive, and lifestyle factors. Furthermore, longer duration of lactation was associated with lower risk for chronic inflammation in middle-aged women. We also observed the mild association between longer duration of lactation and lower triglycerides, but this association was not consistently present with other lipid biomarkers.

Longer duration of lactation has been associated with lower risk for CVD risk and mortality later in life. ${ }^{10-14} 34$ Therefore, lactation behavior in women during reproductive years may influence pathways involved in cardiometabolic health later in life. In a previous investigation, duration of lactation and shorter term follow-up cardiometabolic biomarkers at 3 years postpartum were investigated in women. ${ }^{18}$ Although women who breast fed for longer tended to have lower CRP concentrations at 3 years postpartum, the association did not meet the statistical significance. ${ }^{18}$ However, CRP was measured in young women mostly in their $30 \mathrm{~s}$, and the mean CRP concentrations were low across the participants ranging $0.8-1.1 \mathrm{mg}$ / $\mathrm{dL}$ across lactation duration categories. ${ }^{18}$ Therefore, the investigation may have been underpowered to detect small variations in these young women. Furthermore, inflammatory pathways may be more relevant for women with a history of GDM because GDM is often considered as manifestation of inflammation induced by physiological stress during pregnancy. ${ }^{19}$ In the current analysis among women with a history of GDM, we report that longer duration of lactation is associated with lower risk 
Table 2 Least squares mean $(95 \% \mathrm{Cl})$ concentrations of inflammation, lipid, and liver enzyme biomarkers among middleaged women with history of gestational diabetes, according to lifetime duration of lactation*

\begin{tabular}{|c|c|c|c|c|c|}
\hline & \multicolumn{5}{|c|}{ Lifetime duration of lactation (months) } \\
\hline & 0 & $1-12$ & $12-24$ & $>24$ & $\begin{array}{l}\text { P linear } \\
\text { trend }\end{array}$ \\
\hline \multicolumn{6}{|l|}{ CRP, mg/L } \\
\hline Model 1 & 2.01 (1.57 to 2.59$)$ & 1.91 (1.63 to 2.23$)$ & $1.62(1.38$ to 1.91$)$ & 1.44 (1.25 to 1.67$)$ & 0.003 \\
\hline Model 2 & 2.06 (1.59 to 2.66$)$ & 1.99 (1.70 to 2.34$)$ & $1.64(1.40$ to 1.94$)$ & 1.36 (1.16 to 1.59$)$ & 0.0006 \\
\hline Model 3 & 1.90 (1.47 to 2.45$)$ & 1.98 (1.68 to 2.32$)$ & $1.67(1.42$ to 1.97$)$ & 1.39 (1.19 to 1.62$)$ & 0.003 \\
\hline \multicolumn{6}{|l|}{$\mathrm{IL}-6, \mathrm{pg} / \mathrm{mL}$} \\
\hline Model 1 & 1.30 (0.98 to 1.73$)$ & $1.14(0.96$ to 1.36$)$ & $1.03(0.86$ to 1.24$)$ & $0.96(0.81$ to 1.13$)$ & 0.046 \\
\hline Model 2 & 1.33 (1.00 to 1.77$)$ & $1.20(1.00$ to 1.77$)$ & $1.03(0.86$ to 1.24$)$ & 0.91 (0.76 to 1.09$)$ & 0.01 \\
\hline Model 3 & 1.25 (0.94 to 1.68$)$ & 1.19 (0.99 to 1.42$)$ & $1.04(0.87$ to 1.25$)$ & $0.93(0.78$ to 1.11$)$ & 0.04 \\
\hline \multicolumn{6}{|c|}{ Cholesterol, mg/dL } \\
\hline Model 1 & 189 (182 to 197$)$ & 197 (192 to 202) & 201 (196 to 206) & 201 (196 to 206) & 0.04 \\
\hline Model 2 & 189 (182 to 197$)$ & 197 (192 to 202) & 201 (196 to 206) & 200 (195 to 205) & 0.07 \\
\hline Model 3 & 190 (182 to 198$)$ & 198 (193 to 203) & 201 (196 to 206 ) & 200 (195 to 205) & 0.18 \\
\hline \multicolumn{6}{|c|}{ Triglycerides, mg/dL } \\
\hline Model 1 & $132(119$ to 146$)$ & 116 (109 to 123$)$ & 115 (107 to 122$)$ & 109 (103 to 116$)$ & 0.007 \\
\hline Model 2 & 130 (118 to 144$)$ & 115 (108 to 123$)$ & 115 (108 to 123$)$ & 110 (103 to 117$)$ & 0.03 \\
\hline Model 3 & 128 (115 to 142$)$ & 115 (108 to 123 ) & 115 (108 to 123 ) & 110 (103 to 117$)$ & 0.04 \\
\hline \multicolumn{6}{|c|}{$\mathrm{HDL}-\mathrm{C}, \mathrm{mg} / \mathrm{dL}$} \\
\hline Model 1 & 56.7 (53.2 to 60.4$)$ & 59.8 (57.5 to 62.2$)$ & $60.9(58.5$ to 63.5$)$ & 60.8 (58.6 to 63.1$)$ & 0.15 \\
\hline Model 2 & 57.1 (53.5 to 60.9 ) & 60.1 (57.7 to 62.5$)$ & 60.8 (58.4 to 63.4$)$ & 60.5 (58.2 to 63.0$)$ & 0.31 \\
\hline Model 3 & 58.3 (54.7 to 62.2 ) & 60.1 (57.8 to 62.6$)$ & 60.7 (58.2 to 63.2) & 60.2 (57.9 to 62.6 ) & 0.66 \\
\hline \multicolumn{6}{|c|}{ LDL-C, mg/dL } \\
\hline Model 1 & 101 (95 to 108) & 108 (104 to 112$)$ & 110 (106 to 115$)$ & 110 (106 to 114$)$ & 0.11 \\
\hline Model 2 & 101 (95 to 108) & 108 (104 to 113 ) & 111 (106 to 115 ) & 110 (106 to 115$)$ & 0.12 \\
\hline Model 3 & 102 (95 to 109 ) & 109 (104 to 113) & 111 (106 to 115$)$ & 109 (105 to 114$)$ & 0.27 \\
\hline \multicolumn{6}{|l|}{ ALT, U/L } \\
\hline Model 1 & 21.1 (19.1 to 23.2 ) & 20.1 (19.0 to 21.4$)$ & 19.8 (18.6 to 21.1$)$ & 19.2 (18.1 to 20.3$)$ & 0.10 \\
\hline Model 2 & 20.5 (18.6 to 22.6) & 19.9 (18.7 to 21.2$)$ & 19.8 (18.6 to 21.1$)$ & 19.6 (18.4 to 20.8$)$ & 0.49 \\
\hline Model 3 & 20.4 (18.5 to 22.6 ) & 19.9 (18.7 to 21.2$)$ & 19.8 (18.6 to 21.1$)$ & 19.6 (18.4 to 20.8$)$ & 0.53 \\
\hline \multicolumn{6}{|l|}{ AST, U/L } \\
\hline Model 1 & 26.8 (24.9 to 28.9 ) & 25.6 (24.5 to 26.8$)$ & 25.3 (24.1to 26.6) & 25.5 (24.4 to 26.6$)$ & 0.47 \\
\hline Model 2 & 26.5 (24.6 to 28.6$)$ & 25.5 (24.3 to 26.7$)$ & 25.3 (24.1 to 26.6$)$ & 25.7 (24.6 to 26.9 ) & 0.84 \\
\hline Model 3 & 26.6 (24.6 to 28.7 ) & 25.5 (24.3 to 26.7$)$ & 25.3 (24.1 to 26.6$)$ & 25.7 (24.6 to 26.9 ) & 0.83 \\
\hline \multicolumn{6}{|l|}{ GGT, U/L } \\
\hline Model 1 & 19.0 (16.4 to 21.9$)$ & 19.8 (18.1 to 21.7$)$ & 18.5 (16.8 to 20.3$)$ & 17.0 (15.6 to 18.5$)$ & 0.02 \\
\hline Model 2 & 18.3 (15.8 to 21.2 ) & 19.6 (17.9 to 21.5$)$ & 18.4 (16.8 to 20.2$)$ & 17.4 (15.9 to 19.0$)$ & 0.17 \\
\hline Model 3 & 18.2 (15.7 to 21.1$)$ & 19.6 (17.8 to 21.5$)$ & 18.4 (16.7 to 20.1$)$ & 17.5 (16.0 to 19.2$)$ & 0.22 \\
\hline
\end{tabular}

*Model 1 is adjusted for age at follow-up blood draw. Model 2 is additionally adjusted for ethnicity (white/non-white), family history of diabetes (yes/no), parity, age at first birth (<25, 25-29, 30-34, and $\geq 35$ years), and menopausal status at follow-up blood draw (yes/no). Model 3 is adjusted for model 2 in addition to ever smoking (yes/no), diet quality (high/low), physical activity (high/low), and prepregnancy BMI $\left(\leq 25,25-30\right.$, and $\left.>30 \mathrm{~kg} / \mathrm{m}^{2}\right)$.

ALT, alanine aminotransferase; AST, aspartate aminotransferase; BMI, body mass index; CRP, C reactive protein; GGT, gamma-glutamyl transferase; HDL-C, high-density lipoprotein cholesterol; IL-6, interleukin-6; LDL-C, low-density lipoprotein cholesterol. 
Table 3 ORs $(95 \% \mathrm{Cl})$ for chronic inflammation among women with a history of gestational diabetes, according to lifetime duration of lactation*

\begin{tabular}{llllllll}
\hline & 0month & $\mathbf{1 - 1 2}$ months & 12-24 months & >24 months & $\begin{array}{l}\text { P linear } \\
\text { trend }\end{array}$ & $\begin{array}{l}\text { Per 6-month } \\
\text { increase }\end{array}$ & $\begin{array}{l}\text { Per 1-year } \\
\text { increase }\end{array}$ \\
\hline Model 1 & 1 & $1.13(0.66$ to 1.96$)$ & $0.83(0.48$ to 1.46$)$ & $0.59(0.34$ to 1.02$)$ & 0.002 & $0.93(0.87$ to 0.99$)$ & $0.87(0.77$ to 0.98$)$ \\
Model 2 & 1 & $1.19(0.68$ to 2.09$)$ & $0.82(0.46$ to 1.45$)$ & $0.49(0.27$ to 0.89$)$ & 0.0003 & $0.89(0.82$ to 0.96$)$ & $0.79(0.68$ to 0.92$)$ \\
Model 3 & 1 & $1.33(0.75$ to 2.37$)$ & $0.94(0.52$ to 1.71$)$ & $0.55(0.30$ to 1.03$)$ & 0.001 & $0.90(0.83$ to 0.97$)$ & $0.81(0.69$ to 0.94$)$ \\
\hline
\end{tabular}

${ }^{*}$ Chronic inflammation is assessed using CRP $3 \mathrm{mg} / \mathrm{L}$ cut-off ( $\mathrm{n}=224$ of 675 above $3 \mathrm{mg} / \mathrm{L}$ ). Model 1 is adjusted for age at follow-up blood draw. Model 2 is additionally adjusted for ethnicity (white/non-white), family history of diabetes (yes/no), parity, age at first birth $(<25,25-29,30-34$, and $\geq 35$ years) and menopausal status at follow-up blood draw (yes/no). Model 3 is adjusted for model 2 in addition to ever smoking (yes/no), diet quality (high/low), physical activity (high/low), and prepregnancy BMI ( $\leq 25,25-30$, and $\left.>30 \mathrm{~kg} / \mathrm{m}^{2}\right)$.

$\mathrm{BMI}$, body mass index; CRP, C reactive protein.

for chronic inflammation assessed by lower CRP and IL-6 concentrations in middle-aged women. In addition, we report no significant association between lactation duration and lipid profile in middle-aged women, which is consistent with previous finding in younger women. ${ }^{18}$ Because longer lactation duration has been recently associated with lower risk for non-alcoholic fatty liver disease in women with mean age 49 years $^{20}$ and because liver enzyme biomarkers are predictors for CVD risk, ${ }^{21}$ we investigated the association between lactation duration and liver enzyme biomarkers in middle-aged women with a history of GDM. However, no significant association between lactation duration and liver enzyme biomarkers was evident among these high-risk women in the current investigation. Considering women with a history of GDM generally have higher liver enzyme biomarker concentrations, ${ }^{35}$ lactation behavior during reproductive years may not influence liver enzyme biomarker concentrations substantially in these older women.

In a previous breastfeeding promotion intervention study, longer breastfeeding duration did not result in an important lowering of adiposity or blood pressure in women. ${ }^{36}$ However, this previous intervention may not have investigated the most relevant pathways targeting at risk populations for cardiometabolic disease prevention. Expression of genes involved in inflammatory response is altered in GDM pregnancy, ${ }^{37} 38$ and women with GDM experience higher inflammatory biomarker concentrations during pregnancy. ${ }^{39}$ Therefore, women with a history of GDM accompanied by altered circulating inflammatory factors later in life may be at higher risk for progression to cardiometabolic disease. ${ }^{40}$ Further experimental studies and randomized control trials designed to target inflammatory pathways, especially among women with a history of GDM, are warranted.

Long-term follow-up of women with a history of GDM allowed the current investigation on lactation during reproductive years in relation to an array of cardiometabolic biomarkers in middle age to assess potential cardiometabolic pathways. However, the study has several limitations. First, our study participants were nurses of primarily European ancestry. The observed associations may not be generalizable to other populations with more diverse socioeconomic status and cultural practices. Second, our blood samples were shipped overnight after collection, then processed, and stored for 1-3 years at $-80^{\circ} \mathrm{C}$ before performing biochemical analysis; therefore, the process might have introduced molecular degradation. However, stability of these biomarkers after delay in processing and long-term storage has been documented previously. ${ }^{41} 42$ Third, the observed benefits of lactation may have been confounded by other healthful behaviors, although we attempted to account for these confounders through statistical adjustment of regression models. Therefore, we recommend more carefully designed and controlled future studies to determine the causality. Fourth, because NHS II recruited women aged 25-42 years at the study baseline, the current analysis was not able to capture prospectively the entire group of nulliparous women through each birth. However, in our multiple regression with adjustment for parity, longer lactation during reproductive years remained significantly associated with lower risk for chronic inflammation. Fifth, our lifetime lactation duration variable was derived from three questionnaires administered over 10 years, which was designed to capture cumulative lifetime lactation information. Further clinical investigation is recommended to identify the specific threshold of lactation duration beneficial for women's health.

In summary, longer lifetime duration of lactation was associated with favorable inflammatory biomarker concentrations in middle-aged women. Chronic inflammatory pathways may be involved in previously reported associations between duration of lactation and cardiometabolic disease risk later in life. The current investigation further contributes to the growing evidence that breast feeding, which has the main purpose of supporting child growth and development, also has an important role in women's health. Therefore, continued investigation on the long-term consequences of breast feeding and other behavioral risk factors during reproductive years is warranted from the perspectives of the receiving offspring and from the offering women, especially those who are at high risk for cardiometabolic diseases.

Author affiliations

${ }^{1}$ Department of Epidemiology, Tulane University School of Public Health and Tropical Medicine, New Orleans, Los Angeles, USA 
${ }^{2}$ Department of Nutrition and Epidemiology, Harvard T.H. Chan School of Public Health, Boston, Massachusetts, USA

${ }^{3}$ Channing Division of Network Medicine, Department of Medicine, Brigham and Women's Hospital and Harvard Medical School, Boston, Massachusetts, USA ${ }^{4}$ Division of Intramural Population Health Research, Eunice Kennedy Shriver National Institute of Child Health and Human Development, National Institutes of Health, Bethesda, Maryland, USA

${ }^{5}$ Department of Laboratory Medicine and Pathology, University of Minnesota Medical School, Minneapolis, Minnesota, USA

\section{Twitter Sylvia H Ley @sylviahley}

Acknowledgements We would like to thank the study participants and staff.

Contributors SHL designed and performed the analysis and wrote the paper; FBH and CZ provided essential materials including access to databases; SHL and CZ had primary responsibility for final content; all authors read and approved the final manuscript and contributed in revising the manuscript critically for important intellectual content

Funding This study was supported by the Intramural Research Program of the Eunice Kennedy Shriver National Institute of Child Health and Human Development, National Institutes of Health (contract No. HHSN275201000020C). The Nurses' Health Study II was funded by research grants DK58845, CA50385, P30 DK46200, U01 CA176726, R01 CA67262, and U01 HL145386-01 from the National Institutes of Health. SHL was supported by grant P20GM109036 from the National Institute of General Medical Sciences of the National Institutes of Health.

Competing interests None declared.

Patient consent for publication Not required.

Ethics approval The study protocol was approved by the Institutional Review Board of the Brigham and Women's Hospital and the Human Subjects Committee Review Board of Harvard T.H. Chan School of Public Health in accordance with the Helsinki Declaration of 1975 as revised in 1983 (protocol \# 21 089-101).

Provenance and peer review Not commissioned; externally peer reviewed.

Data availability statement Data are available on reasonable request. Data described in the manuscript, code book, and analytic code are available on the shared cohort computer facility, and access will be made available on request.

Supplemental material This content has been supplied by the author(s). It has not been vetted by BMJ Publishing Group Limited (BMJ) and may not have been peer-reviewed. Any opinions or recommendations discussed are solely those of the author(s) and are not endorsed by BMJ. BMJ disclaims all liability and responsibility arising from any reliance placed on the content. Where the content includes any translated material, BMJ does not warrant the accuracy and reliability of the translations (including but not limited to local regulations, clinical guidelines, terminology, drug names and drug dosages), and is not responsible for any error and/or omissions arising from translation and adaptation or otherwise.

Open access This is an open access article distributed in accordance with the Creative Commons Attribution Non Commercial (CC BY-NC 4.0) license, which permits others to distribute, remix, adapt, build upon this work non-commercially, and license their derivative works on different terms, provided the original work is properly cited, appropriate credit is given, any changes made indicated, and the use is non-commercial. See: http://creativecommons.org/licenses/by-nc/4.0/.

ORCID IDs

Sylvia H Ley http://orcid.org/0000-0003-0084-2630

Mengying Li http://orcid.org/0000-0002-3713-1683

\section{REFERENCES}

1 Benjamin EJ, Muntner P, Alonso A, et al. Heart disease and stroke statistics-2019 update: a report from the American heart association. Circulation 2019;139:e56-28.

2 Reimold SC, Hill JA. Second annual go red for women issue. Circulation 2018;137:761-2.

3 Paynter NP, Balasubramanian R, Giulianini F, et al. Metabolic predictors of incident coronary heart disease in women. Circulation 2018;137:841-53.

4 American Diabetes Association. 2. Classification and Diagnosis of Diabetes: Standards of Medical Care in Diabetes-2019. Diabetes Care 2019;42:S13-28.

5 Tobias DK, Stuart JJ, Li S, et al. Association of history of gestational diabetes with long-term cardiovascular disease risk in a large prospective cohort of US women. JAMA Intern Med 2017;177:1735-42.

6 Kramer CK, Campbell S, Retnakaran R. Gestational diabetes and the risk of cardiovascular disease in women: a systematic review and meta-analysis. Diabetologia 2019;62:905-14

7 Jäger S, Jacobs S, Kröger J, et al. Breast-Feeding and maternal risk of type 2 diabetes: a prospective study and meta-analysis. Diabetologia 2014;57:1355-65.

8 Aune D, Norat T, Romundstad P, et al. Breastfeeding and the maternal risk of type 2 diabetes: a systematic review and doseresponse meta-analysis of cohort studies. Nutr Metab Cardiovasc Dis 2014:24:107-15.

9 Rameez RM, Sadana D, Kaur S, et al. Association of maternal lactation with diabetes and hypertension: a systematic review and meta-analysis. JAMA Netw Open 2019;2:e1913401.

10 Schwarz EB, Ray RM, Stuebe AM, et al. Duration of lactation and risk factors for maternal cardiovascular disease. Obstet Gynecol 2009:113:974-82.

11 Nguyen B, Gale J, Nassar N, et al. Breastfeeding and cardiovascular disease hospitalization and mortality in parous women: evidence from a large Australian cohort study. J Am Heart Assoc 2019;8:e011056.

12 Rajaei S, Rigdon J, Crowe S, et al. Breastfeeding duration and the risk of coronary artery disease. J Womens Health 2019;28:30-6.

13 Natland ST, Nilsen TIL, Midthjell K, et al. Lactation and cardiovascular risk factors in mothers in a population-based study: the HUNT-study. Int Breastfeed J 2012;7:8.

14 Natland Fagerhaug T, Forsmo S, Jacobsen GW, et al. A prospective population-based cohort study of lactation and cardiovascular disease mortality: the HUNT study. BMC Public Health 2013;13:1070.

15 Ley $\mathrm{SH}$. Role of lactation in cardiometabolic health consequences. $J$ Womens Health 2019;28:3-4.

16 Gunderson EP, Lewis CE, Lin Y, et al. Lactation duration and progression to diabetes in women across the childbearing years: the 30-year cardia study. JAMA Intern Med 2018;178:328-37.

17 Ip S, Chung M, Raman G, et al. Breastfeeding and maternal and infant health outcomes in developed countries. Evid Rep Technol Assess 2007:153:1-186.

18 Stuebe AM, Kleinman K, Gillman MW, et al. Duration of lactation and maternal metabolism at 3 years postpartum. J Womens Health 2010;19:941-50.

19 Mclntyre HD, Catalano P, Zhang C, et al. Gestational diabetes mellitus. Nat Rev Dis Primers 2019;5:47.

20 Ajmera VH, Terrault NA, VanWagner LB, et al. Longer lactation duration is associated with decreased prevalence of non-alcoholic fatty liver disease in women. J Hepatol 2019;70:126-32.

21 Targher G, Byrne CD. Circulating markers of liver function and cardiovascular disease risk. Arterioscler Thromb Vasc Bio 2015;35:2290-6.

22 Ruparelia N, Chai JT, Fisher EA, et al. Inflammatory processes in cardiovascular disease: a route to targeted therapies. Nat Rev Cardiol 2017;14:133-44

23 Chait A, Eckel RH, Lipids ERH. Lipids, lipoproteins, and cardiovascular disease: clinical pharmacology now and in the future. $J$ Clin Endocrinol Metab 2016;101:804-14.

24 Solomon CG, Willett WC, Carey VJ, et al. A prospective study of pregravid determinants of gestational diabetes mellitus. JAMA 1997;278:1078-83.

25 Zhang C, Olsen SF, Hinkle SN, et al. Diabetes \& Women's Health (DWH) Study: an observational study of long-term health consequences of gestational diabetes, their determinants and underlying mechanisms in the USA and Denmark. BMJ Open 2019;9:e025517.

26 Colditz GA, Martin P, Stampfer MJ, et al. Validation of questionnaire information on risk factors and disease outcomes in a prospective cohort study of women. Am J Epidemiol 1986;123:894-900.

27 Colditz GA, Stampfer MJ, Willett WC, et al. Reproducibility and validity of self-reported menopausal status in a prospective cohort study. Am J Epidemiol 1987;126:319-25.

28 Willett WC, Sampson L, Stampfer MJ, et al. Reproducibility and validity of a semiquantitative food frequency questionnaire. $A m ~ J$ Epidemiol 1985;122:51-65.

29 Willett W. Reproducibility and Validity of Food-Frequency Questionnaires. In: Nutritional epidemiology. 2nd ed. New York: Oxford University Press, 1998..

30 Chiuve SE, Fung TT, Rimm EB, et al. Alternative dietary indices both strongly predict risk of chronic disease. J Nutr 2012;142:1009-18.

31 Wolf AM, Hunter DJ, Colditz GA, et al. Reproducibility and validity of a self-administered physical activity questionnaire. Int J Epidemiol 1994:23:991-9. 
32 Rimm EB, Stampfer MJ, Colditz GA, et al. Validity of self-reported waist and hip circumferences in men and women. Epidemiology 1990;1:466-73.

33 Sabatine MS, Morrow DA, Jablonski KA, et al. Prognostic significance of the centers for disease Control/American heart association high-sensitivity C-reactive protein cut points for cardiovascular and other outcomes in patients with stable coronary artery disease. Circulation 2007;115:1528-36.

34 Stuebe AM, Rich-Edwards JW, Willett WC, et al. Duration of lactation and incidence of type 2 diabetes. JAMA 2005;294:2601-10.

35 Donnelly SR, Hinkle SN, Rawal S, et al. Prospective study of gestational diabetes and fatty liver scores 9 to 16 years after pregnancy. J Diabetes 2019;11:895-905.

36 Oken E, Patel R, Guthrie LB, et al. Effects of an intervention to promote breastfeeding on maternal adiposity and blood pressure at $11.5 \mathrm{Y}$ postpartum: results from the promotion of breastfeeding intervention trial, a cluster-randomized controlled trial. Am J Clin Nutr 2013;98:1048-56.

37 Magee TR, Ross MG, Wedekind L, et al. Gestational diabetes mellitus alters apoptotic and inflammatory gene expression of trophobasts from human term placenta. $J$ Diabetes Complications 2014:28:448-59.

38 Wojcik M, Zieleniak A, Mac-Marcjanek K, et al. The elevated gene expression level of the $\mathrm{A}(2 \mathrm{~B})$ adenosine receptor is associated with hyperglycemia in women with gestational diabetes mellitus. Diabetes Metab Res Rev 2014;30:42-53.

$39 \mathrm{Xu}$ J, Zhao YH, Chen YP, et al. Maternal circulating concentrations of tumor necrosis factor-alpha, leptin, and adiponectin in gestational diabetes mellitus: a systematic review and meta-analysis. Scientific World J 2014;2014:12

40 Zhu Y, Zhang C. Prevalence of gestational diabetes and risk of progression to type 2 diabetes: a global perspective. Curr Diab Rep 2016;16:7.

41 Gislefoss RE, Grimsrud TK, Mørkrid L. Stability of selected serum proteins after long-term storage in the Janus serum bank. Clin Chem Lab Med 2009;47:596-603.

42 Abraham RA, Agrawal PK, Acharya R, et al. Effect of temperature and time delay in centrifugation on stability of select biomarkers of nutrition and non-communicable diseases in blood samples. Biochem Med 2019;29:020708. 